\title{
Rethinking research: Creating a practice-based agenda for sustainable small-scale healthy food retail
}

\author{
Allison Karpyn, ${ }^{*}$ The Food Trust \\ Hannah Burton-Laurison, ${ }^{\mathrm{b}}$ ChangeLab Solutions
}

Submitted June 11, 2013 / Revised August 28, 2013 / Published online August 30, 2013

Citation: Karpyn, A., \& Burton-Laurison, H. (2013). Rethinking research: Creating a practice-based agenda for sustainable small-scale healthy food retail. Journal of Agriculture, Food Systems, and Community Development, 3(4), 139-143. http://dx.doi.org/10.5304/jafscd.2013.034.015

Copyright (C) 2013 by New Leaf Associates, Inc.

\begin{abstract}
An emerging body of research examines the health and economic impacts of healthy corner store interventions, although implementing valid mechanisms to capture changes in diet remains a challenge. Healthy corner store interventions employ strategies to help corner stores procure, maintain and market healthier foods such as fruits and vegetables, whole grains and low-fat dairy items like skim milk. A recent national convening of partners yielded a series of research and evaluation questions that need answers in order for

a * Corresponding author: Allison Karpyn, PhD, Director, Research and Evaluation; The Food Trust, One Penn Center, 1617 JFK Boulevard, Suite 900, Philadelphia, Pennsylvania 19103 USA; +1-610-909-3154; akarpyn@,thefoodtrust.org

b Hannah Burton Laurison, Senior Planner and Program Director, ChangeLab Solutions; 2201 Broadway, Suite 502; Oakland, California 94612 USA
\end{abstract}

the field to progress. Participants in the Healthy Corner Stores Symposium identified several challenges to developing a sustainable business model for small-scale healthy food retail. This group of practitioners, funders, lenders, academics, and other leaders ranked what they saw as the most promising opportunities for maximizing the positive impact these businesses have on the community. Unique to this forum, the agenda was born from a program-operation perspective and not from the more common approach where an independent researcher evaluates the efficacy of a program or intervention. As efforts to improve food systems emerge, such an approach to research is critical. The central challenges and a prioritized list of research questions are discussed.

\section{Keywords}

bodega, corner store, evaluation, food retail, research, sustainability 


\section{Introduction}

Increasing the quantity and quality of healthy foods offered by corner stores is one promising strategy for improving food access in underserved urban and rural communities (Borradaile et al., 2009). Despite a decade of experience with a variety of approaches to corner-store conversion and an emerging body of evaluation on their impact, many questions remain about the long-term economic viability and health effects of corner-store interventions (Gittelsohn, Rowan, \& Gadhoke, 2012). Funded by the Robert Wood Johnson Foundation, the National Legal and Policy Network to Prevent Childhood Obesity (NPLAN) convened key stakeholders in June 2012 in San Francisco.

Practitioners, funders, lenders, academics, and other thought leaders from a variety of fields were asked to identify opportunities for and barriers to small-scale healthy food retailers as they shift to a sustainable business model. The goal of the symposium was to better understand the technical assistance and financing needs of small store owners so their businesses can maximize the positive impact they have on their communities. As the conversation developed, however, it was clear that many such needs required research.

Overall, several important messages emerged from the meeting, including acknowledging important gaps in funding mechanisms, realizing logistical challenges with sourcing and delivering appropriate quantities of reasonably priced food, expanding policies that support healthy store programs at city and state levels, and a general need to identify mechanisms across sectors to support store-owner capacity to operate profitable small businesses that include healthy food.

\section{Food Security, Health, and Corner Stores}

An interest in working with small stores initially grew out of the food security movement. In the late 1990s, Hartford Food Systems developed one of the first initiatives to improve the quality of healthy foods in stores. Much later, in 2004, The Food Trust and the Johns Hopkins Bloomberg School of Public Health launched the Healthy Corner Stores Network, now an important mechanism for sharing and growing corner-store interventions.
Program funding for corner-store work has also expanded notably in recent years. Through Communities Putting Prevention to Work (CPPW), the American Reinvestment and Recovery Act of 2009 (ARRA) provided US\$650 million in funding from 2010 to 2012 for local preventative health projects, including healthy corner-store interventions (U. S. Department of Health and Human Services, n.d.). The Patient Protection and Affordable Care Act (ACA) has continued funding for similar projects through Community Transformation grants, which distributed over US $\$ 100$ million in 2011. Further, the Healthy Food Financing Initiative, which the departments of Treasury, Health and Human Services, and Agriculture launched in 2011, has committed over US\$50 million to developing food retailers and equipping them to sell healthy, affordable food (PolicyLink, The Food Trust, and The Reinvestment Fund, 2009).

Public health experts are increasingly interested in the food environments where people live and the extent to which healthy and affordable options are within reach (Larson, Story, \& Nelson, 2009). Emerging research shows that people who live near a high number of convenience stores have higher rates of mortality, diabetes, and obesity, while those who live closer to a supermarket, especially if they are part of underserved minority groups, are more likely to meet the Dietary Guidelines for Americans' intake for fruits, vegetables, fat, and saturated fat (U.S. Department of Agriculture and U.S. Department of Health and Human Services, 2011). African American households are statistically less likely to purchase organic foods than white households, which may be linked to access issues in these communities (Mirsch \& Dimitri, 2012). One study found that for each additional supermarket in an African American community, fruit and vegetable consumption increased by over 30 percent (Morland, Diez Roux, \& Wing, 2006). A study of Supplemental Nutrition Assistance Program (SNAP) participants found that those who live further than five miles $(8 \mathrm{~km})$ from their primary grocery store consume significantly less fruit than those who live within one mile (Rose \& Richards, 2004). 


\section{Developing a Practice-based Research Agenda}

Participants in the Healthy Corner Stores Symposium identified several challenges to developing a sustainable business model for small-scale healthy food retail. Yet as challenges were discussed, it was clear that the solution, at least in part, relied on yet unknown information about which approaches would be most likely to maximize long-term impacts. Over the course of the meeting, as challenges and research needs were identified, each was recorded. At the end, participants were asked to prioritize the issues raised. In no specific order, the key issues that emerged centered on challenges and opportunities related to six areas in need of development: (1) financing, (2) distribution, (3) marketing research, (4) policy barriers and opportunities, (5) multisector collaboration, and (6) store owner skills and capacity.

(1) Financing: Presently there are few options for store owners in need of loans of US $\$ 50,000$

US $\$ 100,000$ - an amount which would allow substantial infrastructure and refrigeration improvements. Without needed refrigeration, produce storage (and spoilage) is a significant concern. From the lender perspective, the lack of data or metrics for evaluating risk and the cost and time for underwriting loans to small stores is often prohibitive. Loan institutions require detailed paperwork on expenses and income, and small stores rarely maintain detailed inventory-management and sales systems. Moreover, many community development financial institutions (CDFIs) have minimum loan-size requirements that are larger than appropriate for most corner-store projects. Given these challenges, several research questions emerged.

\section{A. Is it profitable to sell healthy food? \\ B. How can we leverage the impact of grant dollars?}

There is a clear need to examine the business case for selling healthy foods. To date little is known about the profitability of the range of items sold in corner stores and how personnel and refrigeration costs, that might be required in order to carry more healthy food, may shift the balance. Store owners need this kind of data in order to understand the strengths and limitations of adopting a healthy-store model and to develop business plans. Further, there is a need to better understand what mechanisms are possible for banks, community development corporations and financial institutions, and philanthropy to forge in order to maximize the potential funds available to small store owners.

(2) Distribution: Smaller stores have limited storage capacity and lower sales volumes, and as a result they require smaller and more frequent deliveries than their larger counterparts. Small, frequent deliveries exclude stores from wholesale buying and translate to higher prices or compromised quality. Many food distributors have minimum delivery requirements of US $\$ 5,000$ to US $\$ 10,000$ per week, far outside of the needs of the average corner store. What is needed is an understanding of:

\section{A. How can lessons learned from the group purchasing strategies pursued by schools, hospitals, and municipali- ties be applied to healthy corner stores? \\ B. How can advocates for healthy corner stores work with wholesalers and dis- tributors to influence store purchases?}

Although advocates have clearly identified distribution as a barrier to increasing the availability of healthy foods in small stores, the impact of partnerships with wholesalers and distributors has not yet been adequately evaluated. Further, little is known about which strategies for "buying in bulk" are most viable legally and practically.

(3) Marketing Research: As efforts are undertaken to increase the availability of new healthy items, simultaneous efforts to increase demand and maximize marketing efforts are needed. New ideas for promoting healthy foods in stores, including store layout and promotion, however, need testing. The four P's of marketing-price, promotion, placement, and product-certainly are applicable to the corner-store environment. No research has 
been conducted to date, however, about the relative strengths and weaknesses of, or the anticipated lift in sales from, each of those elements. Key questions include:

\section{A. How can store layout and design max- imize sales of healthy products? \\ B. What incentives, if any, do small stores receive from the food and beverage industry? How common are these incentives? \\ C. What are the most effective incentives for healthy food retail?}

Presently, food manufacturers have proprietary understanding of what sells in stores, including smaller stores, and such knowledge needs to be garnered for the purposes of promoting public health. More dialogue and communication between the manufacturing and public health communities will build awareness of where common interests lie and allow each group to develop a parallel understanding of behavioral economics.

(4) Policy barriers and opportunities: Cornerstore owners operate in a complex regulatory environment; their businesses are subject to dozens of local, state, and federal laws. What remains unclear is:

\section{A. How can local municipalities stream- line basic government support to small businesses? \\ B. What role do federal nutrition assis- tance programs play in offering incen- tives for healthy food retail?}

Expedited or coordinated local permitting processes may be a mechanism to create incentives for retailers to improve offerings, particularly in cities with more complex regulatory environments. Further, federal programs such as SNAP and the Women, Infants and Children (WIC) program may hold keys to improving the quality and availability of healthy food options. Additional research is needed to explore, for example, how WIC certification could be leveraged to provide economic incentives for store owners without adding costs to program administration.

(5) Multisector collaboration: Even within the public health sector, advocates for alcohol and tobacco control and healthy eating often work in separate funding spheres and do not coordinate their work and research on the retail environment. At the same time, efforts to understand, for example, current marketing practices or green building design could be important for maximizing a store's potential for success.

\section{A. What are the best practices for evaluat- ing healthy corner-store projects? \\ B. How can funders promote multisector collaboration?}

For the field to advance, there needs to be a richer understanding of the longitudinal health and economic impacts of corner-store efforts and the best metrics to measure them. However, we also need to develop realistic goals for evaluating the short-term impacts of interventions. Researchers and practitioners should create regular opportunities to keep abreast of one another's work and foster multi-sector collaboration from program to policy to research.

(6) Store owner skills and capacity: Shifting the product mix in a store requires an operator to understand how to manage and merchandise fresh produce, how to negotiate favorable terms, how to effectively manage inventory, maintain appropriate insurance coverage, maintain equipment, and engage customers. While these skills are certainly connected to business development generally, a change in product mix represents a significant risk, and in order to sustain changes store owners must be well equipped to maximize sales.
A. Is it possible to develop a matrix to evaluate when loans and/or technical assistance are most appropriate?
B. How can we build a cadre of technical assistance providers?


Given the range of program elements and differences in the size and scope of programs nationally, an opportunity exists to evaluate which types of technical assistance and financing programs have the most impact under which circumstances. Further, it is unclear the extent to which technical service providers across sectors are connected, or best practices and lessons learned about the amount of time needed for store owners to develop critical skills.

\section{Conclusions}

In order to create a sustainable business model for small-scale healthy food retail in underserved urban and rural communities across the United States, we need to fill the gaps in the research, produce muchneeded materials, organize strategy discussions, and coordinate multi-sector efforts. Practice-based approaches to research can align with traditional approaches (Green, 2006), and as demonstrated by the research questions posed here, may well serve to catalyze change. As practitioners strengthen efforts to promote sustainable change in communities (Scheirer, 2013), program and research goals will require increasing alignment. Cross-sector collaboration is also likely to strengthen this approach. As industry leaders begin to infuse the field with their expertise around effective marketing and promotional practices, so too may a new perspective be gained on thinking about data-driven development and the operation of programs to support critical decisions.

\section{References}

Borradaile, K. E., Sherman, S., Vander Veur, S. S., McCoy, T., Sandoval, B., Nachmani, J.,...Foster, G. D. (2009). Snacking in children: The role of urban corner stores. Pediatrics, 124(5), 1293-1298. http://dx.doi.org/10.1542/peds.2009-0964

Gittelsohn, J., Rowan, M., \& Gadhoke, P. (2012). Interventions in small food stores to change the food environment, improve diet, and reduce risk of chronic disease. Preventing Chronic Disease, 9, 110015. http://dx.doi.org/10.5888/pcd9.110015

Green, L. W. (2006). Public health asks of systems science: To advance our evidence-based practice, can you help us get more practice-based evidence? American Journal of Public Health, 96(3), 406-409. http://dx.doi.org/10.2105/AJPH.2005.066035

Larson N. I., Story, M. T., \& Nelson, M. C. (2009).

Neigborhood environments: Disparities in access to healthy foods in the U.S. American Journal of

Preventive Medicine, 36(2), 74-81. http://dx.doi.org/10.1016/j.amepre.2008.09.025

Mirsch, L., \& Dimitri, C. (2012). Access to sustainably produced food: An investigation of organic food availability in Manhattan, New York. Journal of Agriculture, Food Systems, and Community Development, 2(3), 193-209. http://dx.doi.org/10.5304/jafscd.2012.023.001

Morland, K., Diez Roux, A. V., \& Wing, S. (2006). Supermarkets, other food stores, and obesity: The Atherosclerosis Risk in Communities Study. American Journal of Preventive Medicine, 30(4), 333-339. http://dx.doi.org/10.1016/j.amepre.2005.11.003

PolicyLink, The Food Trust and The Reinvestment Fund. (2009). A Healthy Food Financing Initiative: An innovative approach to improve health and spark economic development [Fact sheet]. Available from the PolicyLink website: http://www.policylink.org/site/apps/nlnet/ content2.aspx? $=1 \mathrm{kIXLbMNJrE \& b}=5136581 \&$ $\mathrm{ct}=8047759$

Rose, D., \& Richards, R. (2004). Food store access and household fruit and vegetable use among participants in the US Food Stamp Program. Public Health Nutrition, 7(8), 1081-1088. http://dx.doi.org/10.1079/PHN2004648

Scheirer, M. A. (2013). Linking sustainability research to intervention types. American Journal of Public Health, 103(4), e73-e80. http://dx.doi.org/10.2105/AJPH.2012.300976

U.S. Department of Agriculture and U.S. Department of Health and Human Services. (2011). Dietary guidelines for Americans, 2010. Washington, D.C.: Authors. Retrieved from http://www.dietaryguidelines.gov

U.S. Department of Health and Human Services. (n.d.). HHS Communities Putting Prevention to Work Initiative. http://www.hhs.gov/recovery/programs/cppw/ factsheet.html 